\title{
Vitamin therapy in critically ill patients: focus on thiamine, vitamin C, and vitamin D
}

\author{
Karin Amrein ${ }^{1 *}\left(\mathbb{D}\right.$, Heleen M. Oudemans-van Straaten ${ }^{2}$ and Mette M. Berger ${ }^{3}$
}

๑ 2018 The Author(s). This article is an open access publication

\section{Introduction}

Recent hypothesis-generating studies have sparked new interest in an old concept: adjuvant vitamin therapy in critical illness or "metabolic resuscitation". In this minireview, we report on the most promising players in this setting: thiamine (vitamin B1), vitamin $C$, and vitamin $D$. Their main characteristics are summarized in Table 1 (see also electronic supplementary material, ESM).

\section{Thiamine}

\section{Function}

Thiamine is the precursor of thiamine pyrophosphate (TPP), the essential coenzyme of several decarboxylases required for glucose metabolism, the Krebs cycle, the generation of ATP, the pentose phosphate pathway, and the production of NADPH $[1,2]$.

\section{Thiamine and acute illness}

Apart from lactic acidosis due to failure of pyruvate to enter the Krebs cycle, two potentially fatal deficiency conditions are known: cardiac (or wet) beriberi, and Gayet-Wernicke encephalopathy. Thiamine deficiency was first described in critically ill patients in the 1980s and is recognized as being associated with mortality [2]. Hypermetabolic states and parenteral nutrition without micronutrients predispose to acute deficiency of thiamine [1]. Thiamine deficiency is present in $20-70 \%$ of septic shock patients, depending on the cutoff value used [2]. Analytical issues associated with TPP determination in inflammation complicate the diagnosis of deficiency. High-performance liquid chromatography (HPLC) on

\footnotetext{
*Correspondence: karin.amrein@medunigraz.at

${ }^{1}$ Division of Endocrinology and Diabetology, Department of Internal

Medicine, Medical University of Graz, Graz, Austria

Full author information is available at the end of the article
}

whole blood together with erythrocyte determination represents the most reliable method (ESM).

\section{Dose and future}

Preventive interventions have shown controversial results. A randomized trial using a single dose of $300 \mathrm{mg}$ thiamine versus placebo before elective cardiac surgery [3] normalized plasma thiamine without affecting postoperative lactate concentrations.

In contrast, the metabolic effects of thiamine justify further investigations in sepsis. A randomized trial conducted in 88 septic shock patients $(2 \times 200 \mathrm{mg}$ thiamine/ day for 7 days) showed decreasing lactate levels. A significant difference in time to death was observed in favor of thiamine $(\mathrm{P}=0.047)$, with lower mortality (13 versus $46 \%$ in controls) in the subgroup of patients with deficiency [4]. The post hoc analysis showed that the thiamine group had lower creatinine levels with less progression to renal replacement therapy than the placebo group [5]. In a highly controversial, small before-after trial, a combination of thiamine, hydrocortisone, and vitamin $C$ in sepsis was associated with a large reduction of organ dysfunction [6]; this finding requires validation. In view of the current evidence, the low risks, and the low costs, administration of liberal amounts of thiamine (300 mg I.V. daily in at-risk patients and $100 \mathrm{mg}$ in all other patients during the first $48 \mathrm{~h}$ in the ICU) should be considered as it enables metabolic handling of dextrose $5 \%$.

\section{Vitamin C}

Vitamin C (ascorbate) has pleiotropic effects. During critical illness, acute deficiency of vitamin $\mathrm{C}$ is common (eTable 2, ESM) but generally goes unnoticed because the symptoms mimic critical illness and rapid measurement of plasma concentrations is not available. Acute vitamin $\mathrm{C}$ deficiency may contribute to hypotension, exaggerated inflammation, capillary leakage,

\section{实




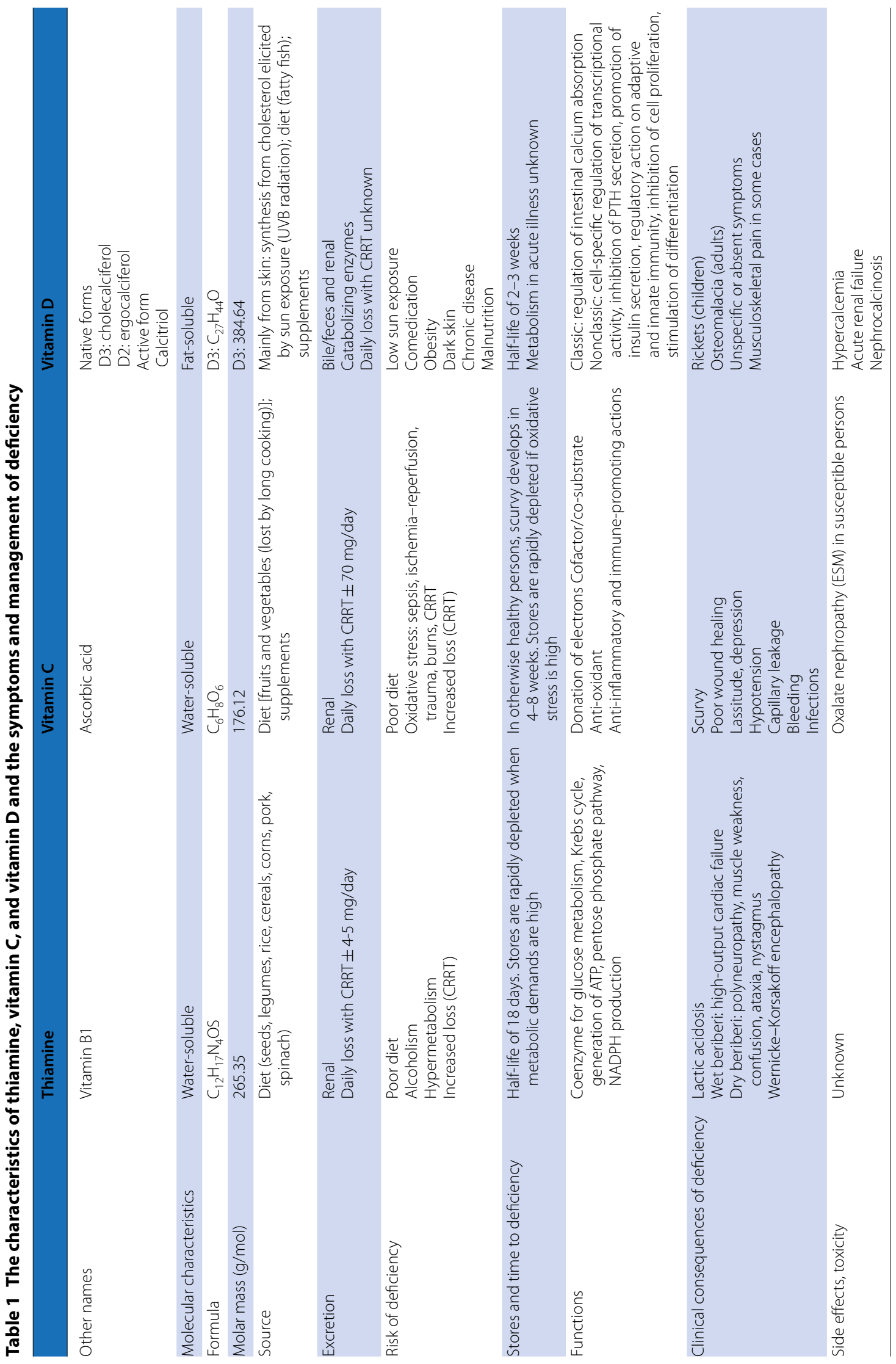




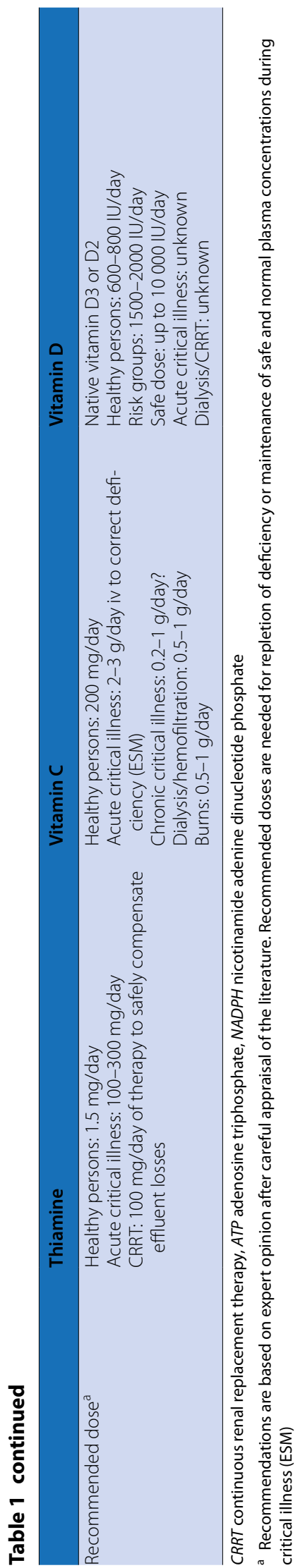

microcirculatory compromise, oxidative organ injury, and impaired immune defense and wound healing.

\section{Function}

Vitamin $C$ is an electron donor, which accounts for its myriad functions [7]. It is cofactor/cosubstrate for the biosynthesis of neurotransmitters (noradrenaline, serotonin), cortisol, peptide hormones (vasopressin), and collagen. Vitamin $C$ is the most potent water-soluble antioxidant. It directly scavenges radicals and recycles other antioxidants, and protects the endothelium by promoting collagen synthesis and maintaining endothelial vasodilation and barrier function [8]. Vitamin $C$ can limit the inflammatory response and ischemia-reperfusion injury, improve host defense, wound healing, and mood, and reduce pain (ESM).

\section{Vitamin C and acute illness}

Critical illness abruptly increases vitamin $\mathrm{C}$ requirements (ESM). Activated neutrophils accumulate vitamin C, while the adrenals secrete accumulated vitamin $\mathrm{C}$, triggering cortisol production [7]. Although redistributed, vitamin $\mathrm{C}$ is likely lost during cell degradation. Furthermore, while some of the oxidized vitamin $\mathrm{C}$ is normally recycled, some is lost if reducing mechanisms fail [7]. Additionally, vitamin $C$ is consumed during the synthesis of norepinephrine, peptide hormones, and cortisol.

\section{Dose and future}

The optimal dose and plasma concentration of vitamin C remain unknown. Several trials (eTable 2, ESM) using a repletion dose (0.5-3 g/day) reported improved recovery from organ failure [8]. The results of recent preliminary trials (eTable 3, ESM) suggest that a short course of pharmacological doses in severe sepsis $(50-200 \mathrm{mg} / \mathrm{kg} /$ day or $6 \mathrm{~g} /$ day with or without hydrocortisone and thiamine [6]) reduces vasopressor dose and promotes recovery, but the tendency towards lower mortality needs confirmation (eTable 3, ESM) $[6,9,10]$. High doses seem to be safe (ESM). Pathophysiological findings suggest that pharmacological doses of intravenous vitamin $C$ should probably be limited to the early phase, because low levels of radicals are crucial for (intra)cellular signaling.

\section{Vitamin D}

Humans can produce vitamin $D$ endogenously under conditions of sufficient UVB exposure. Vitamin D is a precursor to a steroid hormone with a specific nuclear receptor (vitamin D receptor) present in a variety of different cell types and organs. 


\section{Function}

Vitamin D acts via pleiotropic, cell-specific genomic and nongenomic pathways [11]. Target organs that are particularly relevant in the ICU include muscle, lung, heart, immune system, and kidney. In contrast to vitamin $\mathrm{C}$ and thiamine, testing for vitamin D is fast, widely available, and sufficiently reliable.

\section{Vitamin D and acute illness}

Depending on definition and population, vitamin D deficiency [usually defined as serum $25(\mathrm{OH}) \mathrm{D} \leq 20 \mathrm{ng} / \mathrm{ml}$ ] is present in $30-60 \%$ of ICU patients worldwide. Since 2009 , observational studies have clearly shown that vitamin D deficiency is linked to excess morbidity and mortality in adults and children in the ICU [12]. Preliminary data using novel methods suggest that glutathione and glutamate pathway metabolism, which are important for redox regulation and immunomodulation, are affected by vitamin D status [13].

So far, worldwide $<700$ patients have been treated for vitamin $\mathrm{D}$ deficiency in a very limited number of randomized controlled intervention trials, recently summarized in different meta-analyses [14]. The VITdAL-ICU study $(n=475)$ did not find a difference in the length of hospital stay between groups, but there was a significant reduction in mortality in the predefined subgroup of patients with severe vitamin D deficiency [15]. The most recent meta-analysis concludes that vitamin D in the ICU may be associated with mortality reduction [12].

\section{Dose and future}

The optimal native vitamin $\mathrm{D}$ dose in critical illness is unknown, but up to 10,000 IU daily is considered safe; the standard dose of 600-800 IU, however, is ineffective in the acute setting. The logical question, "Can vitamin D supplementation during or before critical illness improve outcomes?", is currently the subject of intensive research aiming to include $>5000$ patients in the VIOLET study (NCT03096314) and the VITDALIZE study (NCT03188796).

\section{Summary, conclusions and outlook}

Vitamin C, vitamin D, and thiamine are promising micronutrients for adjuvant therapy in severe acute illness. We recommend early supplementation to prevent/ treat deficiency (Table 1). Due to increased needs, critically ill patients need amounts higher than the daily recommended dose, but pharmacological dosing requires further studies (ESM).

Important considerations include the following:
- The requirements for vitamin $C$, vitamin $\mathrm{D}$, and thiamine are likely higher in severe illness than in health (ESM).

- The beneficial effect on clinical outcomes will be greater in depleted subjects.

- Determination of thiamine and vitamin $\mathrm{C}$ deficiency is not possible without major delay and may be invalidated by improper sampling.

- A better understanding of the role of micronutrients in critical illness may be achievable by means of novel methods including genomics and metabolomics.

- The time is ripe for pragmatic randomized trials in different high-risk populations exhibiting overwhelming oxidative stress using different treatment regimes.

\section{Electronic supplementary material}

The online version of this article (https://doi.org/10.1007/s00134-018-5107-y) contains supplementary material, which is available to authorized users.

\section{Author details}

${ }^{1}$ Division of Endocrinology and Diabetology, Department of Internal Medicine, Medical University of Graz, Graz, Austria. ${ }^{2}$ Department of Adult Intensive Care, VU University Medical Centre, De Boelelaan 1117, 1081 HV Amsterdam, The Netherlands. ${ }^{3}$ Service of Adult Intensive Care and Burns, Lausanne University Hospital-CHUV, Lausanne, Switzerland.

\section{Acknowledgements}

Open access funding provided by Medical University of Graz.

\section{Open Access}

This article is distributed under the terms of the Creative Commons Attribution-NonCommercial 4.0 International License (http://creativecommons.org/ licenses/by-nc/4.0/), which permits any noncommercial use, distribution, and reproduction in any medium, provided you give appropriate credit to the original author(s) and the source, provide a link to the Creative Commons license, and indicate if changes were made.

Received: 6 October 2017 Accepted: 20 February 2018 Published online: 8 March 2018

\section{References}

1. Leite HP, de Lima LF (2016) Metabolic resuscitation in sepsis: a necessary step beyond the hemodynamic? J Thorac Dis 8:E552-E557

2. Mallat J, Lemyze M, Thevenin D (2016) Do not forget to give thiamine to your septic shock patient! J Thorac Dis 8:1062-1066

3. Luger M, Hiesmayr M, Koppel P, Sima B, Ranz I, Weiss C, Konig J, Luger E, Kruschitz R, Ludvik B, Schindler K (2015) Influence of intravenous thiamine supplementation on blood lactate concentration prior to cardiac surgery: a double-blinded, randomised controlled pilot study. Eur J Anaesthesiol 32:543-548

4. Donnino MW, Andersen LW, Chase M, Berg KM, Tidswell M, Giberson T, Wolfe R, Moskowitz A, Smithline H, Ngo L, Cocchi MN, Center for Resuscitation Science Research Group (2016) Randomized, double-blind, placebo-controlled trial of thiamine as a metabolic resuscitator in septic shock: a pilot study. Crit Care Med 44:360-367

5. Moskowitz A, Andersen LW, Cocchi MN, Karlsson M, Patel PV, Donnino MW (2017) Thiamine as a renal protective agent in septic shock. a secondary analysis of a randomized, double-blind. Placebo-controlled Trial. Ann Am Thorac Soc 14:737-741 
6. Marik PE, Khangoora V, Rivera R, Hooper MH, Catravas J (2017) Hydrocortisone, vitamin C, and thiamine for the treatment of severe sepsis and septic shock: a retrospective before-after study. Chest 151:1229-1238

7. Padayatty SJ, Levine M (2016) Vitamin C: the known and the unknown and Goldilocks. Oral Dis 22:463-493

8. Oudemans-van Straaten HM, Spoelstra-de Man AM, de Waard MC (2014) Vitamin C revisited. Crit Care 18:460

9. Fowler AA, Syed AA 3rd, Knowlson S, Sculthorpe R, Farthing D, DeWilde C, Farthing CA, Larus TL, Martin E, Brophy DF, Gupta S, Nursing Medical Respiratory Intensive Care Unit, Fisher BJ, Natarajan R (2014) Phase I safety trial of intravenous ascorbic acid in patients with severe sepsis. J Trans Med 12:32

10. Zabet MH, Mohammadi M, Ramezani M, Khalili H (2016) Effect of highdose Ascorbic acid on vasopressor's requirement in septic shock. J Res Pharm Pract 5:94-100

11. Holick MF (2007) Vitamin D deficiency. N Engl J Med 357:266-281
12. Putzu A, Belletti A, Cassina T, Clivio S, Monti G, Zangrillo A, Landoni G (2017) Vitamin D and outcomes in adult critically ill patients. A systematic review and meta-analysis of randomized trials. J Crit Care 38:109-114

13. Lasky-Su J, Dahlin A, Litonjua AA, Rogers AJ, McGeachie MJ, Baron RM, Gazourian L, Barragan-Bradford D, Fredenburgh LE, Choi AMK, Mogensen KM, Quraishi SA, Amrein K, Christopher KB (2017) Metabolome alterations in severe critical illness and vitamin D status. Crit Care 21:193

14. Amrein K, Martucci G, McNally JD (2017) When not to use meta-analysis: analysing the meta-analyses on vitamin D in critical care. Clin Nutr 36(6):1729-1730

15. Amrein K, Schnedl C, Holl A, Riedl R, Christopher KB, Pachler C, Urbanic Purkart T, Waltensdorfer A, Munch A, Warnkross H, Stojakovic T, Bisping E, Toller W, Smolle KH, Berghold A, Pieber TR, Dobnig H (2014) Effect of high-dose vitamin D3 on hospital length of stay in critically ill patients with vitamin D deficiency: the VITdAL-ICU randomized clinical trial. JAMA $312: 1520-1530$ 